\title{
DATA ENVELOPMENT ANALYSIS ON EFFICIENCY EVALUATION OF IRRIGATION- FERTILIZATION SCHEMES FOR WINTER WHEAT IN NORTH CHINA
}

\author{
Songhao Shang ${ }^{1, *}$, Xiaomin Mao ${ }^{2}$ \\ ${ }^{1}$ State Key Laboratory of Hydroscience and Engineering, Department of Hydraulic and \\ Hydropower Engineering, Tsinghua University, Beijing 100084, China \\ ${ }^{2}$ College of Water Conservancy \& Civil Engineering, China Agricultural University, Beijing \\ 100083, China \\ * Corresponding author, Address: Department of Hydraulic and Hydropower Engineering, \\ Tsinghua University, Beijing 100084, China, Tel: +86-10-62783176, fax: +86-10-627730 \\ 46, Email:shangsh@mail.tsinghua.edu.cn
}

Abstract: Crop production is a process of multiple inputs (water and nutrients, etc.), and the relationships between the inputs and crop yield are very complex. This study used a model for data envelopment analysis (DEA) to evaluate the efficiency of irrigation-fertilization schemes for winter wheat in North China. The field experiments were conducted at the Xiaohe Irrigation Experiment Station in Central Shanxi Province, China. Sixteen irrigation-fertilization schemes, the combinations of four levels of irrigation (irrigation volume from 0 to $300 \mathrm{~mm}$ ) and four levels of fertilizer (0, low, moderate and high), were considered in the experiments. Experimental results revealed that irrigation and fertilization have significant impact on wheat yield and water use efficiency (WUE). For schemes without fertilization, wheat yield and WUE tend to be the lowest for all the irrigation levels and vary little with irrigation volume. With a specified irrigation volume, wheat yield and WUE tend to increase with fertilizer level. At a specified fertilizer level, wheat yield tends to increase with irrigation volume, while WUE is less influenced by irrigation volume. Among the sixteen schemes, ten were evaluated to be DEA efficient or nearly DEA efficient. The results indicated that proper combination of irrigation and fertilization is necessary for efficient use of water and fertilizer. Low fertilizer level with no irrigation and low, moderate or high fertilizer levels with more irrigation volume are generally effective for winter wheat production.

Please use the following format when citing this chapter:

Shang, S. and Mao, X., 2009, in IFIP International Federation for Information Processing, Volume 293, Computer and Computing Technologies in Agriculture II, Volume 1, eds. D. Li, Z. Chunjiang, (Boston: Springer), pp. 39-48. 
Keywords: crop yield, data envelopment analysis, efficiency evaluation, fertilizer, irrigation

\section{INTRODUCTION}

Irrigation and fertilization are effective measures to increase crop yield, especially in arid, semi-arid and sub-humid areas (Cao, 2001). However, improper irrigation and fertilization practices may result in low water and nutrients use efficiency, groundwater depletion (Yang et al., 2006) and contamination to groundwater and water body (Zhu and Chen, 2002). Therefore, it has become a major concern in irrigation and fertilization management to increase crop yield and water use efficiency and to decrease contamination caused by nutrients loss.

The impact of irrigation and fertilization on crop yield, water use efficiency (WUE) has been extensively investigated for different crops and regions (e.g., Al-Kaisi and Yin, 2003; Li, et al., 2004; Aujla et al., 2005; Mandal et al., 2005). However, with multiple inputs (water and nutrients, etc.) for output (crop yield) and their complex relationships, it is difficult to evaluate the efficiency of irrigation-fertilization schemes using a single index, such as the crop yield, water use efficiency or nutrients use efficiency. For a multi-criteria evaluation problem, the evaluating procedure and results may also be bias due to personal preferences, attitudes and knowledge, etc. (Srdjevic et al., 2005).

Crop production function (CPF) quantitatively describes the relationships between crop yield and main influencing factors, i.e., water index shown as irrigation volume or evapotranspiration and nutrients indexes shown as fertilizer applied or nutrients uptake, etc. CPF is usually expressed as empirical functions in two types, one relating crop yield with seasonal water and nutrients indexes in the forms of quadratic, square root, MitscherlichBaule, linear or nonlinear von Leibig (Llewelyn and Featherstone, 1997), whereas the other with indexes partitioned over different growth stages (Sharma et al., 1992). Artificial neural networks (ANNs) have also been used in the modeling of CPF (Shang et al., 2003). However, CPFs are generally obtained through regression analysis or training of ANNs based on experiment results. The regression results represent the mean level of crop production with different irrigation and fertilization schemes, which is different from the concept of production function in microeconomics. With these CPFs, we can judge whether an irrigation-fertilization scheme is efficient or not compared with the mean level, but unable to judge which scheme is the most efficient and how to improve the inefficient ones.

To measure the efficiency of decision making units (DMUs) with multiple inputs and outputs, Charnes et al. (1978) proposed the first model of data 
envelopment analysis (DEA), named CCR model. DEA uses mathematical programming techniques and models to evaluate the relative efficiency for each DMU. Evaluation results from DEA are sufficiently objective, because little personal judgment is considered. Since 1978, DEA has been applied in a wide range of fields, such as education, health care, banking, armed forces, market research, transportation and manufacturing ( $\mathrm{Zhu}, 2003$ ). In water and fertilizer management fields, DEA starts to be applied to evaluate the performance of irrigation district (Rodríguez-Díaz et al., 2004), variable-rate fertilization (Ma et al., 2004) and reservoir system (Srdjevic et al., 2005), etc.

Winter wheat is one of main food crops in North China. Although irrigation is necessary to obtain higher crop yield, water available for irrigation is limited because of the increasing water shortage in this area. Therefore, it is necessary to study proper irrigation-fertilization schemes with limited water supply. The main objectives of this study are to study the effect of irrigation and fertilizer (nitrogen and phosphorus) on wheat yield and water use efficiency, and to evaluate the efficiency of irrigationfertilization schemes for winter wheat using DEA.

\section{MATERIALS AND METHODS}

\subsection{Area description and experiment treatment}

Field experiment was conducted at the Xiaohe Irrigation Experiment Station $\left(112^{\circ} 40^{\prime} \mathrm{E}, 37^{\circ} 38^{\prime} \mathrm{N}\right.$ and $782.6 \mathrm{~m}$ above sea level) during the growing season of winter wheat in 2003-2004. The Station belongs to the Xiaohe Water Resources Administration of Shanxi Province in North China. Mean annual precipitation is approximately $450 \mathrm{~mm}$ with $70 \%$ falling in the period from June to September. Winter wheat is one of main crops in this area and grows mainly in dry seasons from October to next June. Precipitation in this period is only approximately $150 \mathrm{~mm}$, which is much less than the water requirement of winter wheat of over $500 \mathrm{~mm}$ (Wang and Sun, 2003). Irrigation water for this irrigation area mainly comes from the Xiaohe River and groundwater. However, available water for irrigation has been decreasing in recent years due to the decease of river runoff and groundwater depletion.

In the growing season of winter wheat in 2003/04, we carried out experiment at 24 plots to study the impact of irrigation and fertilization on winter wheat yield. Each plot was $20 \mathrm{~m}^{2}$.

Four irrigation treatments (I0 to I4) with different times and volume of irrigation were considered (Table 1). At the time of sowing, diammonium 
phosphate with $15 \%$ nitrogen $(\mathrm{N})$ and $42 \%$ phosphorus pentoxide $\left(\mathrm{P}_{2} \mathrm{O}_{5}\right)$ was applied simultaneously at the rates of $0,375,750$ and $1125 \mathrm{~kg} \mathrm{hm}^{-2}$. With irrigation in the jointing stage, complementary fertilization of urea with $46 \%$ $\mathrm{N}$ was applied at the rates of $0,112.5,225$ and $337.5 \mathrm{~kg} \mathrm{hm}^{-2}$. The combination of irrigation and fertilization treatments were given in Table 1. Among these sixteen treatments, four with moderate fertilizer rate were replicated three times.

Table 1. Irrigation and fertilization treatments for winter wheat in 2003/2004

\begin{tabular}{|c|c|c|c|c|c|c|c|c|}
\hline \multirow{2}{*}{ No. } & \multirow{2}{*}{ Treatments } & \multicolumn{5}{|c|}{ Irrigation volume at different growing stages $(\mathrm{mm})$} & \multicolumn{2}{|c|}{ Fertilization rate $\left(\mathrm{kg} / \mathrm{hm}^{2}\right)$} \\
\hline & & Winter & Jointing & Heading & Milking & Total & Seeding & Jointing \\
\hline 1 & I0-F0-0 & & & & & 0 & 0 & 0 \\
\hline 2 & $\mathrm{I} 0-\mathrm{F} 1-0$ & & & & & 0 & 375 & 0 \\
\hline 3 & I0-F2-0 & & & & & 0 & 750 & 0 \\
\hline 4 & $\mathrm{I} 0-\mathrm{F} 3-0$ & & & & & 0 & 1125 & 0 \\
\hline 5 & $\mathrm{I} 1-\mathrm{F} 0-0$ & & 45 & & & 45 & 0 & 0 \\
\hline 6 & $\mathrm{I} 1-\mathrm{F} 1-1$ & & 45 & & & 45 & 375 & 112.5 \\
\hline 7 & I1-F2-2 & & 45 & & & 45 & 750 & 225 \\
\hline 8 & I1-F3-3 & & 45 & & & 45 & 1125 & 337.5 \\
\hline 9 & $\mathrm{I} 3-\mathrm{F} 0-0$ & 75 & 60 & & 45 & 180 & 0 & 0 \\
\hline 10 & I3-F1-1 & 75 & 60 & & 45 & 180 & 375 & 112.5 \\
\hline 11 & I3-F2-2 & 75 & 60 & & 45 & 180 & 750 & 225 \\
\hline 12 & I3-F3-3 & 75 & 60 & & 45 & 180 & 1125 & 337.5 \\
\hline 13 & I4-F0-0 & 75 & 75 & 75 & 75 & 300 & 0 & 0 \\
\hline 14 & I4-F $1-1$ & 75 & 75 & 75 & 75 & 300 & 375 & 112.5 \\
\hline 15 & I4-F2-2 & 75 & 75 & 75 & 75 & 300 & 750 & 225 \\
\hline 16 & I4-F3-3 & 75 & 75 & 75 & 75 & 300 & 1125 & 337.5 \\
\hline
\end{tabular}

The wheat variety used for the study is Jing-9428, a common variety of wheat grown in that area. The seeds were sown on October 7, 2003 at the rate of $338 \mathrm{~kg} \mathrm{ha}^{-2}$. The row spacing was $25 \mathrm{~cm}$ and the sowing depth was 5 $\mathrm{cm}$.

Irrigation and fertilization was applied according to the experiment design. A flow meter was used to control the amount of water applied. Irrigation for winter, jointing, heading and milking stages were applied on December 11, 2003, April 19, May 7 and May 29, 2004, respectively. Diammonium phosphate was applied at the time of sowing and urea with irrigation in the jointing stage.

Meteorological factors, including air temperature, humidity, wind speed, sunshine hours and precipitation, were monitored during the growing stage of winter wheat. Volumetric soil water content was monitored using neutron probe. Access tubes were installed at the center of each experiment plot. Soil water content was monitored at approximately 10-days' interval from sowing to harvesting for every $20 \mathrm{~cm}$ soil layer from the surface to $2.0 \mathrm{~m}$ in depth. After harvesting on June 19, 2004, wheat yield of each irrigation-fertilization treatment was measured.

\subsection{Water use efficiency}

Water use efficiency was calculated using the following equation. 
WUE $=0.1 Y / E T$

where WUE is the water use efficiency $\left(\mathrm{kg} \mathrm{m}^{-3}\right), Y$ is the crop yield $(\mathrm{kg}$ $\mathrm{hm}^{-2}$ ), ET is the corresponding evapotranspiration $(\mathrm{mm})$, and 0.1 is a constant for units conversion. ET under soil water stress conditions was calculated using the method of single crop coefficient (Allen et al., 1998).

$$
\mathrm{ET}=K_{\mathrm{s}} K_{\mathrm{c}} \mathrm{ET}_{0}
$$

where $\mathrm{ET}_{0}$ is the reference evapotranspiration, $K_{\mathrm{c}}$ is the crop coefficient, and $K_{\mathrm{s}}$ is the coefficient describing the effect of water stress on evapotranspiration. $K_{\mathrm{s}}$ was calculated from soil water content obtained from a soil water balance model, which was modified after the model of Allen et al. (1998) by introducing an empirical equation (Wang and Sun, 2003) to describe soil water flux through the bottom of the root zone.

\subsection{CCR model for data envelopment analysis}

For DMUs with single input and output, the efficiency can be defined as the ratio of output to input. For DMUs with multiple inputs and outputs, Charnes et al. (1978) proposed to measure the efficiency with the maximum ratio of weighted outputs to weighted inputs subjected to the condition that the similar ratios for all DMUs are less than or equal to 1 . In contrast to statistical approaches characterized by evaluations of DMUs relative to an average DMU, DEA is an extreme point method that compares each DMU to all other DMUs with weights chosen to favor the DMU being considered.

Suppose $n$ DMUs to be evaluated. DMU $j(j=1,2, \ldots, n)$ uses $m$ inputs $x_{i j}$ $(i=1,2, \ldots, m)$ to produce $s$ outputs $y_{r j}(r=1,2, \ldots, s)$. Using DEA, the efficiency of each DMU is evaluated separately. When DMU $j_{0}$ with inputs $x_{i 0}(i=1,2, \ldots, m)$ and outputs $y_{r 0}(r=1,2, \ldots, s)$ is under evaluation, the inputorientated CCR model with non-Archimedean $\varepsilon$ can be expressed as (Zhu, 2003; Wei, 2004)

$$
\begin{aligned}
& \operatorname{min.} \quad\left[\theta-\varepsilon\left(\sum_{i=1}^{m} S_{i}^{-}+\sum_{r=1}^{s} S_{r}^{+}\right)\right] \\
& \text {subject to } \sum_{j=1}^{n} X_{i j} \lambda_{j}+S_{i}^{-}=\theta X_{i 0}, i=1,2, \ldots, m \\
& \sum_{j=1}^{n} Y_{r j} \lambda_{j}-S_{r}^{+}=Y_{r 0}, r=1,2, \ldots, S \\
& S_{i}^{-} \geq 0, i=1,2, \ldots, m \\
& \lambda_{j} \geq 0, j=1,2, \ldots, n \\
& S_{r}^{+} \geq 0, r=1,2, \ldots, S
\end{aligned}
$$

where $\theta$ represents the relative efficiency, $\lambda_{j}$ is the weight of DMU $j, S_{i}^{-}$ and $S_{r}^{+}$are input and output slacks, respectively.

Suppose the optimal solution of the CCR model is $\left(\theta^{*}, \lambda_{j}^{*}, S_{i}^{-*}, S_{r}^{+*}\right)^{\mathrm{T}}$. If 
$\theta^{*}=1$, then the DMU under evaluation is DEA efficient when $S_{i}^{-*}=0$ and $S_{r}^{+*}=0$, or weakly DEA efficient otherwise. If $\theta^{*}<1$, then the DMU under evaluation is inefficient. For an inefficient DMU, other DMUs with non-zero optimal $\lambda_{j}^{*}$ can be used to define a hypothetical efficient DMU, which shows how inputs can be decreased to make the DMU under evaluation efficient (Zhu, 2003).

To evaluate the efficiency of irrigation-fertilization schemes, each irrigation-fertilization scheme was regarded as a DMU. Three inputs were considered, including total evapotranspiration (ET), total nitrogen applied $(N)$ and phosphorus pentoxide applied $(P)$. Only one output, wheat yield, was considered.

\section{RESULTS AND DISCUSSION}

\subsection{Effects of irrigation and fertilizer level on wheat yield}

Both irrigation and fertilizer level have significant influence on the wheat yield, and wheat yield tends to increase with irrigation volume and fertilizer applied (Fig. 1).

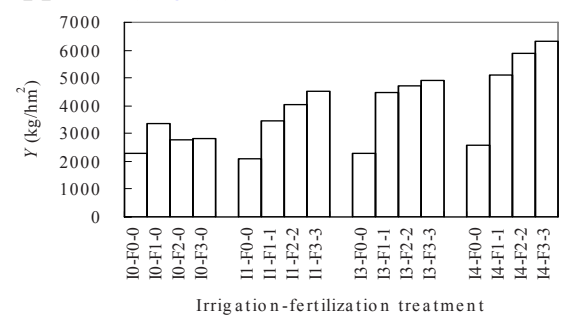

Fig. 1: Wheat yield $(Y)$ for different irrigation-fertilization treatments.



Fig. 2: WUE for different irrigation-fertilization treatments.

Wheat yield response to irrigation varies with fertilizer level. Without fertilizer application in the whole growing period, wheat yield is the lowest for all irrigation schemes and its variation with irrigation volume is small. This might be caused by severe soil nutrients stress to crop growth. It increases almost linearly with irrigation volume for non-zero fertilizer levels (Fig. 1 and Table 2). Results of linear regression between wheat yield and irrigation volume show that $1 \mathrm{~mm}$ irrigation volume can result in the yield increment of approximately $6.1,9.2$ and $9.9 \mathrm{~kg} \mathrm{hm}^{-2}$ for low, moderate and high fertilizer levels, respectively.

On the other hand, wheat yield response to fertilizer level varies with irrigation volume. Wheat yield of low fertilizer level was significantly higher 
than that of the zero fertilizer level, and the increment ratios were $46 \%, 65 \%$, $50 \%, 96 \%$ and $99 \%$ for irrigation schemes I0, I1, I3 and I4, respectively. However, with more fertilizer applied (moderate and high fertilizer levels), the increment of wheat yield became less. Especially for I0, wheat yield of moderate and high fertilizer levels were even lower than the yield of low fertilizer level. This indicates that appropriate nutrients rate for maximum yield with severe water stress is low and too much fertilizer application may result in the decrease of wheat yield. The relationship between wheat yield and fertilizer rate can be described by CPFs with a peak value, such as the quadratic or square root CPFs (Llewelyn and Featherstone, 1997).

Table 2. Irrigation and fertilization treatments for winter wheat in 2003/2004

\begin{tabular}{cccc}
\hline Treatments & Evapotranspiration $(\mathrm{mm})$ & Wheat yield $\left(\mathrm{kg} \mathrm{hm}^{-2}\right)$ & Water use efficiency $\left(\mathrm{kg} \mathrm{m}^{-3}\right)$ \\
\hline I0-F2-0 & $291 \mathrm{~A}$ & $2759 \mathrm{~A}$ & $0.95 \mathrm{~A}$ \\
I1-F2-2 & $327 \mathrm{~B}$ & $4035 \mathrm{~B}$ & $1.23 \mathrm{~B}$ \\
I3-F2-2 & $380 \mathrm{C}$ & $4705 \mathrm{C}$ & $1.24 \mathrm{~B}$ \\
I4-F2-2 & $466 \mathrm{D}$ & $5901 \mathrm{D}$ & $1.27 \mathrm{~B}$ \\
\hline
\end{tabular}

Note: Data are the mean values of three replications. Values of the same column followed by different letters are significantly different at both $P=0.05$ and $P=0.01$ based on LSD test.

\subsection{Effects of irrigation and fertilizer level on evapotranspiration and water use efficiency}

Total water requirement of winter wheat, or evapotranspiration without water stress, was approximately $552 \mathrm{~mm}$. Evapotranspiration was nearly the same for the same irrigation volume with different fertilizer level (Table 3). It averaged to be $289 \mathrm{~mm}, 327 \mathrm{~mm}, 380 \mathrm{~mm}$ and $466 \mathrm{~mm}$ for different irrigation treatments, showing a linear increasing trend of evapotranspiration with irrigation volume. The regression analysis of evapotranspiration (ET) and irrigation volume $(I)$ yielded the following results:

$\mathrm{ET}=0.56 I+292, R^{2}=0.981$, degree of freedom $n-2=22$.

The regression result indicates that $1 \mathrm{~mm}$ irrigation volume can result in the ET increment of approximately $0.56 \mathrm{~mm}$. In other words, the amount of initial soil water used for evapotranspiration declines with irrigation volume.

WUE was less influenced by irrigation compared with wheat yield (Fig. 2). Due to low yield of irrigation treatments I0, WUE of I0 was lower than the others. Both wheat yield and evapotranspiration increased with irrigation volume, so WUE of I1, I3 and I4 change little at a specified fertilizer level. For moderate fertilizer level, least significant difference (LSD) test shows that WUE of I1, I3 and I4 are not significantly different (Table 2). However, WUE of this group, approximately $1.25 \mathrm{~kg} \mathrm{~m}^{-3}$, are significantly higher than WUE of I0, $0.95 \mathrm{~kg} \mathrm{~m}^{-3}$.

WUE response to fertilizer level was similar to the wheat yield. WUE also increased significantly from zero fertilizer level to low fertilizer level, especially for large irrigation volume. WUE of I3 and I4 at low fertilizer 
level nearly double the values at zero fertilizer level. With more fertilizer applied (moderate and high fertilizer levels), the increment of WUE also becomes less. For irrigation treatment I0, WUE also has a peak value at low fertilizer level due to the peak of wheat yield.

Table 3. Inputs, output and results of DEA for different irrigation-fertilization schemes

\begin{tabular}{|c|c|c|c|c|c|c|c|c|c|c|}
\hline \multirow[b]{2}{*}{ No. } & \multirow[b]{2}{*}{ Treatments } & \multicolumn{3}{|c|}{ Input } & \multirow{2}{*}{$\begin{array}{c}\text { Output } \\
Y \\
\left(\mathrm{~kg} / \mathrm{hm}^{2}\right)\end{array}$} & \multirow{2}{*}{$\begin{array}{c}\text { Relative } \\
\text { Efficiency } \\
\theta^{*}\end{array}$} & \multicolumn{3}{|c|}{ Input Slacks } & \multirow{2}{*}{$\begin{array}{c}\text { Output } \\
\text { Slack } \\
S_{\mathrm{Y}}{ }^{*}\end{array}$} \\
\hline & & $\begin{array}{c}\text { ET } \\
(\mathrm{mm})\end{array}$ & $\begin{array}{c}N \\
\left(\mathrm{~kg} / \mathrm{hm}^{2}\right)\end{array}$ & $\begin{array}{c}P \\
\left(\mathrm{~kg} / \mathrm{hm}^{2}\right)\end{array}$ & & & $S_{\mathrm{ET}}{ }^{*}$ & $S_{\mathrm{N}}{ }^{*}$ & $S_{\mathrm{P}}{ }^{*}$ & \\
\hline 1 & I0-F0-0 & 288 & 0 & 0 & 2288 & 1 & 0 & 0 & 0 & 0 \\
\hline 2 & I0-F1-0 & 288 & 56 & 158 & 3345 & 1 & 0 & 0 & 0 & 0 \\
\hline 3 & I0-F2-0 & 291 & 113 & 315 & 2759 & 0.77 & 0 & 0 & 99 & 0 \\
\hline 4 & I0-F3-0 & 286 & 169 & 473 & 2802 & 0.75 & 0 & 0 & 169 & 0 \\
\hline 5 & I1-F0-0 & 327 & 0 & 0 & 2089 & 0.80 & 0 & 0 & 0 & 0 \\
\hline 6 & I1-F1-1 & 329 & 108 & 158 & 3453 & 0.88 & 0 & 0 & 0 & 0 \\
\hline 7 & I1-F2-2 & 327 & 216 & 315 & 4035 & 0.92 & 0 & 0.2 & 0 & 0 \\
\hline 8 & I1-F3-3 & 326 & 324 & 473 & 4520 & 1 & 0 & 0 & 0 & 0 \\
\hline 9 & $\mathrm{I} 3-\mathrm{F} 0-0$ & 379 & 0 & 0 & 2276 & 0.76 & 0 & 0 & 0 & 0 \\
\hline 10 & I3-F1-1 & 380 & 108 & 158 & 4465 & 1 & 0 & 0 & 0 & 0 \\
\hline 11 & I3-F2-2 & 380 & 216 & 315 & 4705 & 0.95 & 0 & 0.1 & 0 & 0 \\
\hline 12 & I3-F3-3 & 379 & 324 & 473 & 4920 & 0.95 & 0 & 0 & 0 & 0 \\
\hline 13 & I4-F0-0 & 465 & 0 & 0 & 2556 & 0.69 & 0 & 0 & 0 & 0 \\
\hline 14 & I4-F 1-1 & 466 & 108 & 158 & 5095 & 0.99 & 0 & 0 & 0 & 0 \\
\hline 15 & I4-F2-2 & 466 & 216 & 315 & 5901 & 1 & 0 & 0 & 0 & 0 \\
\hline 16 & I4-F3-3 & 467 & 324 & 473 & 6310 & 1 & 0 & 0 & 0 & 0 \\
\hline
\end{tabular}

Notes: ET-evapotranspiration, $N$-total nitrogen applied, $P$-phosphorus pentoxide applied, $Y$ wheat yield.

\subsection{Relative efficiency of irrigation-fertilization schemes}

The relative efficiency of irrigation-fertilization schemes were evaluated using the CCR model for DEA. Among sixteen irrigation-fertilization schemes considered, six were evaluated to be DEA efficient, including I0F0-0, I0-F1-0, I1-F3-F3, I3-F1-F1, I4-F2-2 and I4-F3-3 (Table 3). Another three schemes, I4-F1-1, I3-F2-2 and I3-F3-3, were all close to DEA efficient. Each of these efficient or nearly efficient schemes had higher wheat yield and/or higher WUE in a certain group of schemes.

Among schemes without irrigation (I0), schemes with zero and low fertilizer level (I0-F0-0 and I0-F1-0) were both DEA efficient. With minimum water and fertilizer inputs, the scheme I0-F0-0 ranked second in wheat yield and first in WUE among all schemes without fertilization. However, this scheme is unsustainable because soil fertility may be deteriorated. The scheme I0-F1-0 ranked first in both wheat yield and WUE among I0. Schemes I0-F2-0 and I0-F3-0 were both inefficient with excess phosphorus pentoxide. Therefore, low fertilizer level is recommended for rain-fed winter wheat in the study area.

Among schemes with only once irrigation in the jointing stage (I1), the scheme with high fertilizer level (I1-F3-3) was DEA efficient, which ranked first in wheat yield among I1 and first in WUE among all sixteen schemes. Therefore, this scheme was recommended if less irrigation water is available. 
Among schemes with three times of irrigation (I3), the scheme with low fertilizer level (I3-F1-1) was DEA efficient with wheat yield and WUE 5\% to $10 \%$ lower than that of moderate and high fertilizer levels (I3-F2-2 and I3F3-3), but the fertilizer applied was only $1 / 2$ and $1 / 3$ of the moderate and high fertilizer levels. I3-F2-2 and I3-F3-3 were both close to DEA efficient.

Among schemes with four times of irrigation (I4), the schemes with moderate and high fertilizer levels (I4-F2-2 and I4-F3-3) were both DEA efficient, with the former ranked second and the latter ranked first in both wheat yield and WUE. The scheme with low fertilizer level (I4-F1-1) was also very close to DEA efficient.

\section{CONCLUSION}

Experiment results of winter wheat with different irrigation-fertilization schemes revealed that irrigation and fertilization have significant impact on wheat yield and WUE. Wheat yield and WUE without fertilization are lower for all irrigation levels and change little with irrigation volume, and they tend to increase with fertilizer level at a specified irrigation volume. Wheat yield also tends to increase with irrigation volume at a specified fertilizer level. However, WUE is less influenced by irrigation volume.

DEA provide an objective approach to evaluate the efficiency of irrigation-fertilization schemes. Main advantages of the DEA are that DEA is applicable to evaluate schemes with multiple inputs and outputs using mathematical programming models and the evaluation results are objective. Irrigation-fertilization schemes for winter wheat in Xiaohe Irrigation Area in North China were evaluated using DEA. The results indicate that proper combination of irrigation and fertilization is necessary for efficient use of water and nutrients. Combinations of low fertilizer level with no irrigation, or the low, moderate and high fertilizer levels with more irrigation volume are generally effective for winter wheat production.

\section{ACKNOWLEDGEMENTS}

This work is supported by National Natural Science Foundation of China (No. 50579027) and NCET Program. 


\section{REFERENCES}

Al-Kaisi MM, Yin X. 2003. Effects of nitrogen rate, irrigation rate, and plant population on corn yield and water use efficiency. Agron. J., 95, 1475-1482.

Allen RG, Pereira LS, Raes D, et al. 1998. Crop evapotranspiration - Guidelines for computing crop water requirements. FAO, Rome.

Aujla MS, Thind HS, Buttar GS. 2005. Cotton yield and water use efficiency at various levels of water and $\mathrm{N}$ through drip irrigation under two methods of planting. Agric. Water Manage., 71, 167-179

Cao WX. 2001. An introduction to crop (in Chinese). Higher Education Press, Beijing.

Charnes A, Cooper WW, Rhodes E. 1978. Measuring the efficiency of decision making units. Eur. J. Oper. Res., 2, 429-444.

Li WL, Li WD, Li ZZ. 2004. Irrigation and fertilizer effects on water use and yield of spring wheat in semi-arid regions. Agric. Water Manage., 67, 35-46.

Llewelyn RV, Featherstone AM. 1997. A comparison of crop production functions using simulated data for irrigated corn in western Kansas. Agr. Syst., 54, 521-538.

$\mathrm{Ma} \mathrm{CL}, \mathrm{Wu} \mathrm{CC}$, Zhang SH, et al. 2004. Decision making method for variable-rate fertilization based on data envelopment analysis and artificial neural network (in Chinese).

T. Chinese Soc. Agric. Eng., 20(2), 152-155.

Mandal KG, Hati KM, Misra AK, et al. 2005. Irrigation and nutrient effects on growth and water-yield relationship of wheat (Triticum aestivum L.) in Central India. J. Agron. Crop Sci., 191, 416-425.

Rodríguez-Díaz JA, Camacho-Poyato E, López-Luque R. 2004. Application of data envelopment analysis to studies of irrigation efficiency in Andalusia. J. Irrig. Drain. Eng., $130,175-183$.

Shang SH, Wei YL, Zhou ZW. 2003. Modeling crop yield response to water and nitrogen with artificial neural networks based on genetic algorithms. In Kang S.Z., Davies, B., Shan, L., Cai, H.J. (eds), Water-Saving Agriculture and Sustainable Use of Water and Land Resources. Shaanxi Science and Technology Press, Xi'an, pp. 288-292.

Sharma BD, Jalota SK, Kar S, et al. 1992. Effect of nitrogen and water uptake on yield of wheat. Fert. Res. 31, 5-8.

Srdjevic B, Medeiros YDP, Porto RLL. 2005. Data envelopment analysis of reservoir system performance. Comput. Oper. Res. 32, 3209-3226.

Wang YR, Sun XP. 2003. Agricultural Water-saving theory and High Water Use Efficiency Pattern for crops in Shanxi (in Chinese). China Science and Techonlogy Press, Beijing.

Wei QL. 2004. Data envelopment analysis (in Chinese). Science Press, Beijing.

Yang YH, Watanabe M, Zhang XY, et al. 2006. Optimizing irrigation management for wheat to reduce groundwater depletion in the piedmont region of the Taihang Mountains in the North China Plain. Agric. Water Manage., 82, 25-44.

Zhu J. 2003. Quantitative models for performance evaluation and benchmarking: data envelopment analysis with spreadsheets and DEA Excel solver. Kluwer Academic Publishers, Boston.

Zhu ZL, Chen DL. 2002. Nitrogen fertilizer use in China - Contributions to food production, impacts on the environment and best management strategies. Nutr. Cycl. Agroecosys. 63, 117-127. 